\section{As tecnologias de comunicação na memória dos idosos}

\author{
Communication technologies \\ in the elderly's memory
}

\author{
Michel Carvalho da Silva \\ Doutorando em Ciências Humanas e Sociais pela \\ Universidade Federal do ABC (UFABC). Atualmente é \\ jornalista na Câmara Municipal de Cubatão (SP). Atua \\ como professor colaborador do projeto de extensão \\ Universidade Aberta à Terceira Idade (Uati), \\ Santos (SP), Brasil. \\ michel.carvalho@ufabc.edu.br
}

Resumo: O trabalho recorre a depoimentos dos idosos a fim de compreender as transformações sociais ocorridas a partir da interação desse grupo populacional com os meios de comunicação. Por intermédio da dinâmica "Minha primeira vez", cada participante da Uati rememora seu primeiro contato com o aparelho celular, o computador, a $\mathrm{TV}$, o cinema e o rádio. A oficina foi desenvolvida na perspectiva da educomunicação, que se trata de um campo de intervenção social nascido a partir da inter-relação comunicação e educação.

Palavras-chave: Comunicação. Memória. Tecnologia. Idosos.

Abstract: The article calls upon the elderly's testimonies in order to understand the social transformations that occurred from the interaction between this population group and the communication means. Through the workshop called "My first time", each UATI (Universidade Aberta da Terceira Idade - Open University for the Elderly) participant recalls his/her first contact with the cell phone, the computer, the TV, the cinema and the radio. The workshop was developed from the education-communication perspective, which is a field of social intervention that emerged from the interrelationship between communication and education.

Keywords: Communication. Testimony. Technology. The elderly.

\section{Introdução}

Os indicadores de saúde e de qualidade de vida dos últimos anos revelam uma significativa melhoria nas condições de vida das populações tanto de países desenvolvidos quanto daqueles que ainda não concluíram o processo de desenvolvimento econômico e social. Isso resultou na elevação da expectativa de vida, que, no caso brasileiro, representa um salto de 33,4 anos em 1910 para os 73,1 em 2010 (IBGE, 2010). Com isso, o país apresenta um novo perfil demográfico. Hoje, temos cerca de 23 milhões de idosos.

Essa mudança de paradigma fica mais evidente quando pensamos na região metropolitana da Baixada Santista, que, nos últimos dez anos, apresentou um aumento de $44,84 \%$ de população de idosos (sessenta anos ou mais), maior que a média do estado de São Paulo (43,84\%) e do Brasil (41,65\%). A região contabiliza hoje em torno de 151 mil pessoas nessa faixa etária (IBGE, 2010). Em números absolutos, o total de idosos em Santos passou de 65.200, em 2000, para 80.353 em 2010, o que significa que de cada cinco moradores da cidade, um tem mais de sessenta anos de idade. 
Dessa maneira, o município santista é um lócus privilegiado para o desenvolvimento de atividades de extensão voltadas para a terceira idade e para a investigação científica desse estrato social.

O projeto de extensão Universidade Aberta à Terceira Idade (Uati) iniciou suas atividades em 2006 no campus Baixada Santista da Universidade Federal de São Paulo (Unifesp). A iniciativa atende estudantes na unidade central do campus e no centro de convivência da Zona Noroeste, na cidade de Santos (SP), e se propõe a desenvolver um modelo de universidade para pessoas acima de sessenta anos, de ambos os sexos, em consonância com uma perspectiva crítica de saúde, educação e sociedade.

A proposta político-pedagógica da Uati considera que os idosos têm plenas condições de continuar aprendendo, produzindo e transmitindo saberes, motivo pelo qual é tão importante aproximá-los dos estudantes da graduação e do universo acadêmico. As aulas buscam desenvolver temáticas que despertem o interesse dos estudantes de modo a envolvê-los e facilitem sua compreensão do mundo, favorecendo a criação e o fortalecimento de vínculos intergeracionais (Silva et al., 2015).

A oficina "A comunicação e a tecnologia na vida do idoso", objeto desse relato de experiência, foi desenvolvida nos dias 22 e 29 de maio de 2015 como parte das atividades do projeto de extensão Uati nas unidades Zona Noroeste e Silva
Jardim, tendo como responsável o autor do presente artigo.

Situado o contexto em que se desenvolve essa oficina com os estudantes da Uati, passaremos a refletir sobre três tópicos conceituais: as potencialidades da terceira idade, a memória do idoso, e a educomunicação como linguagem e estratégia de conversação. Por fim, apresentaremos o perfil dos participantes da Uati em relação ao uso das tecnologias de comunicação e analisaremos a relação dos idosos com esses dispositivos a partir de seus depoimentos.

\section{As potencialidades dos idosos}

Ricardo Moragas (2010), referência nos estudos sobre gerontologia social, nos apresenta três conceituações de velhice: cronológica, funcional e etapa vital. A primeira está relacionada a um aspecto objetivo, ou seja, o fato de se atingir 65 anos. Apesar de considerar a idade um dado importante, o autor critica essa classificação meramente etária por levar em conta mais o mero transcurso do tempo e menos a qualidade do tempo decorrido, os acontecimentos vivenciados e as condições ambientais que a rodearam.

O segundo tipo de conceituação está associado ao emprego do termo velho como sinônimo de incapaz ou limitado, traduzindo a relação tradicional entre velhice e vulnerabilidade. Essa represen- 
tação ajuda a explicar o isolamento social do idoso, que, por ter suas limitações ressaltadas socialmente, não conseguiria conviver com naturalidade com crianças, jovens e adultos.

Por último, temos o conceito denominado etapa vital, que enxerga o idoso como um sujeito com muitas qualidades que devem ser exploradas, apesar das limitações que, com o passar do tempo, vão se agravando, especialmente nos últimos anos de vida. Moragas destaca que os idosos têm características únicas e distintas, como a serenidade, a experiência, a maturidade, a perspectiva de vida pessoal e social.

Uma pessoa idosa possui várias experiências, conhecimentos e saberes que um jovem pode não ter. Mas este possui a vitalidade de que o velho carece. Se a sociedade valoriza unicamente o desenvolvimento fisiológico, são evidentes as limitações dos idosos. Contudo se ela aprecia a qualidade psíquica social, então há muitas oportunidades para eles. (Moragas, 2010, p. 37)

Por vivermos em uma sociedade que valoriza o vigor físico, a velocidade e a imagem, o idoso não tem suas potencialidades desenvolvidas adequadamente. Por isso, é imperioso dedicar maior atenção aos nexos entre produção do conhecimento e envelhecimento ativo, a partir da recuperação das memórias do passado que auxiliam na compreensão dos fenômenos sociais contemporâneos, como a quase onipresença das tecnologias de comunicação no cotidiano das pessoas.

\section{A memória do idoso: recuperando o passado}

A memória é objeto de investigação de diferentes áreas do conhecimento, sendo que o conceito varia de acordo com a natureza do fenômeno e do enfoque da pesquisa. De forma geral, Jacques Le Goff (2003) entende que a memória, como propriedade de conservar determinadas informações, remete-nos primeiramente a um conjunto de funções psíquicas, responsáveis pela atualização de impressões passadas ou que o homem representa como passadas.

Maurice Halbwachs (2006) destaca que pela memória o passado vem à tona, misturando-se com as percepções imediatas, deslocando-as, ocupando todo o espaço da consciência. Segundo o autor, para se ter uma memória coletiva é preciso interligar as diversas memórias dos sujeitos que fazem parte do grupo identificado como detentor daquela memória. Por isso, Halbwachs não encara a memória como um reviver, mas como um ato de reconstrução, resgatando vivências localizadas no tempo, no espaço e no conjunto de relações sociais.

Ecléa Bosi (2007), que tem destacado trabalho sobre memória social a partir das lembranças de velhos, considera a velhice tanto um destino biológico quanto uma 
categoria social. Ela defende que os idosos têm a função social de lembrar, sendo que a memória deles pertence à coletividade. A autora também entende que a evidência oral, transformando os "objetos" de estudo em "sujeitos", contribui para uma história mais verdadeira.

Para Guita Debert (2004), o velho é depositário de uma experiência e de um saber único e exclusivo dado pelo tempo vivido. Para a antropóloga, a memória é um bem valioso que, assim como a história, deve ser transmitida à juventude. Por conta disso, cada idoso, sendo portador dessa memória, deve ter sua respeitabilidade recuperada e garantida pelos mais jovens.

As memórias dos idosos servem de marcas referenciais para a compreensão do processo histórico-cultural. Os relatos de experiências e vivências que marcam momentos decisivos da população idosa registram sonhos, medos, frustrações, escolhas e valores que entrelaçam três dimensões: o real, o simbólico e o imaginário.

É comum observar idosos que não recordam de passagens cotidianas, mas lembram com exatidão de situações ocorridas há muitos anos. Isso acontece porque a memória se desloca com mais facilidade para evocações passadas devido ao seu significado especial, ficando o registro do dia a dia dificultado pelo desgaste cognitivo, comum da idade, e, sobretudo, pelo pouco valor que lhe é atribuído.

$\mathrm{O}$ exercício da memória aciona dois movimentos: a busca de uma realidade esquecida no tempo e a idealização dessa realidade, transformada e recriada constantemente. Essa tentativa de resgatar lembranças e reminiscências ajuda a evitar que a imaginação dos idosos se torne improdutiva, além de contribuir com o processo de autoavaliação, que se constitui como um verdadeiro mergulho interior: "Comprovou-se que levar o idoso a olhar seu percurso de vida desde o passado, trilhando o presente até chegar ao futuro, poderá ajudá-lo a perceber melhor o que já conquistou e o que o motiva na vida" (Novaes, 2007, p. 106).

A memória tanto favorece o conhecimento do passado na organização ordenada do tempo, localizando os eventos numa sucessão cronológica, quanto contribui para a identidade pessoal e social dos mais velhos. Ao acionar suas lembranças, o idoso acaba reunindo fragmentos que serão conservados na memória, associando começos e fins no tempo e no espaço.

A memória social possui caráter dialógico e, por isso, não representa somente o passado. Ela está ligada ao presente ao relacionar valores, preceitos e crenças. Segundo Novaes, a memória, por sua natureza dinâmica, é um processo conflitual e está inserida num movimento de constantes mudanças, sendo uma construção do presente, através do resgate do passado, que se insere no campo das possibilidades do futuro.

Jorge L. Bondia (2002) nos fala que a aceleração em que o sujeito moderno vive impede a experiência e, consequente- 
mente, a memória. Para ele, tudo se passa demasiadamente depressa, numa vivência pontual e fragmentada.

A velocidade com que nos são dados os acontecimentos e a obsessão pela novidade, pelo novo, que caracteriza o mundo moderno, impedem a conexão significativa entre acontecimentos. Impedem também a memória, já que cada acontecimento é imediatamente substituído por outro que igualmente nos excita por um momento, mas sem deixar qualquer vestígio. (Bondia, 2002, p. 23)

Assim, ao reter determinados fatos por um longo tempo e recuperá-los no momento da troca de experiências, os idosos se contrapõem a esse processo de aceleração temporal, exercitando sua capacidade de leitura do mundo.

Entender as formas como se dão as apropriações, os usos e as negativas com relação aos meios de comunicação nos leva a relacionar os processos entre o passado e o presente, bem como os sentidos elaborados pelos mais envelhecidos. No entanto, Marialva Barbosa considera que é "no processo de vida, na distinção que se faz em relação ao que já foi vivido, que se constrói o tempo histórico, tempo dos sujeitos e das ações do homem no mundo" (2015, p. 156). Dessa forma, o passado só pode ser recuperado parcialmente a partir de rastros e vestígios, ou seja, o passado tal como se deu não pode ser recuperado, e sim presumido como poderia ter sido.

\section{Oolhar educomunicativo}

O resgaste das lembranças dos idosos em relação aos meios de comunicação foi desenvolvido na perspectiva educomunicativa a fim de criar um espaço de troca de saberes em que os estudantes da Uati/BS se sentissem protagonistas do processo, num contraponto à tradição verticalizada e canônica dos ambientes de ensino.

A centralidade da comunicação na vida das pessoas vem transformando vários setores da sociedade, particularmente o da educação. Educar já não é mais exclusividade de pais e professores. Com o avanço da midiatização (Hjarvard, 2012), a informação circula rapidamente e o conhecimento é construído de forma pulverizada. Ser mediador nessa nova conjuntura comunicacional é uma das características do educomunicador.

Na década de 1980, o filósofo Mário Kaplun, baseado na pedagogia de Paulo Freire, cria o neologismo educomunicação para se referir a um novo campo de intervenção social. As discussões sobre essa emergente área do conhecimento foram ampliadas pelo Núcleo de Comunicação e Educação da Universidade de São Paulo (NCE-USP) no final da década de 1990.

De acordo com Citelli e Costa (2011), a educomunicação não indica apenas a existência de uma nova área que trabalha na interface comunicação e educação, mas também sinaliza para uma circunstância histórica, segundo a qual os mecanismos 
de produção, circulação e recepção do conhecimento e da informação se fazem considerando o papel de centralidade da comunicação. Para os autores, a educomunicação busca compreender a educação formal, informal e não formal no interior do ecossistema comunicativo, entendido como o entorno educacional difuso e descentralizado no qual estamos imersos.

A educomunicação, como uma rede de relações inclusivas, abertas e criativas, atende a uma demanda da sociedade contemporânea, suprindo a lacuna entre o saber formal e o midiático. Dessa maneira, uma oficina educomunicativa requer uma metodologia voltada para a dialogicidade $\mathrm{e}$ a convivência, não sendo possível realizá-la sumariamente de cima para baixo, de forma dirigida e preocupada apenas com resultados práticos.

Mais do que uma estratégia pedagógica, a educomunicação é uma interface de sociabilidade que tem o objetivo de melhorar o coeficiente expressivo e comunicativo dos sujeitos envolvidos num processo educativo, rompendo com a cultura do silêncio, tão presente nesse grupo populacional.

Os idosos, quando estimulados a compartilhar suas experiências de vida, têm a possibilidade de produzir novos conhecimentos, reforçar vínculos e desenvolver maior autoestima. Dessa maneira, o diálogo estabelecido entre os idosos, de forma livre e espontânea, pode ajudar a construir um ambiente favorável para um envelhecimento realmente ativo, superan- do os estereótipos de improdutividade, solidão e adoecimento.

\section{A experiência da oficina: apontamentos sobre os relatos}

A oficina "A comunicação e a tecnologia na vida do idoso" foi iniciada com a exibição de um trecho do desenho animado Jetsons (Hanna-Barbera, 1962), que retrata a "era espacial", mostrando como seria a humanidade em 2062: carros voadores, cidades suspensas, trabalho automatizado, aparelhos eletrônicos que executam todas as tarefas cotidianas e androides como empregados domésticos. O objetivo desse momento foi despertar a reflexão dos idosos sobre como se imaginava o futuro naquela época. Vale destacar que muitos participantes da oficina afirmaram que chegaram a pensar, quando eram crianças, que o mundo seria como aquele retratado no desenho animado, ou seja, bem mais automatizado e tecnológico do que realmente é hoje.

Depois desse panorama inicial, aplicamos um questionário para verificar o uso das tecnologias de comunicação pelos 76 idosos que participaram da oficina nas duas unidades da Uati. Como alguns deles apresentavam dificuldades de leitura e escrita, o responsável pela oficina auxiliou-os no momento de preencher o questionário, tomando cuidado para não direcionar as respostas. Vejamos os resultados: 


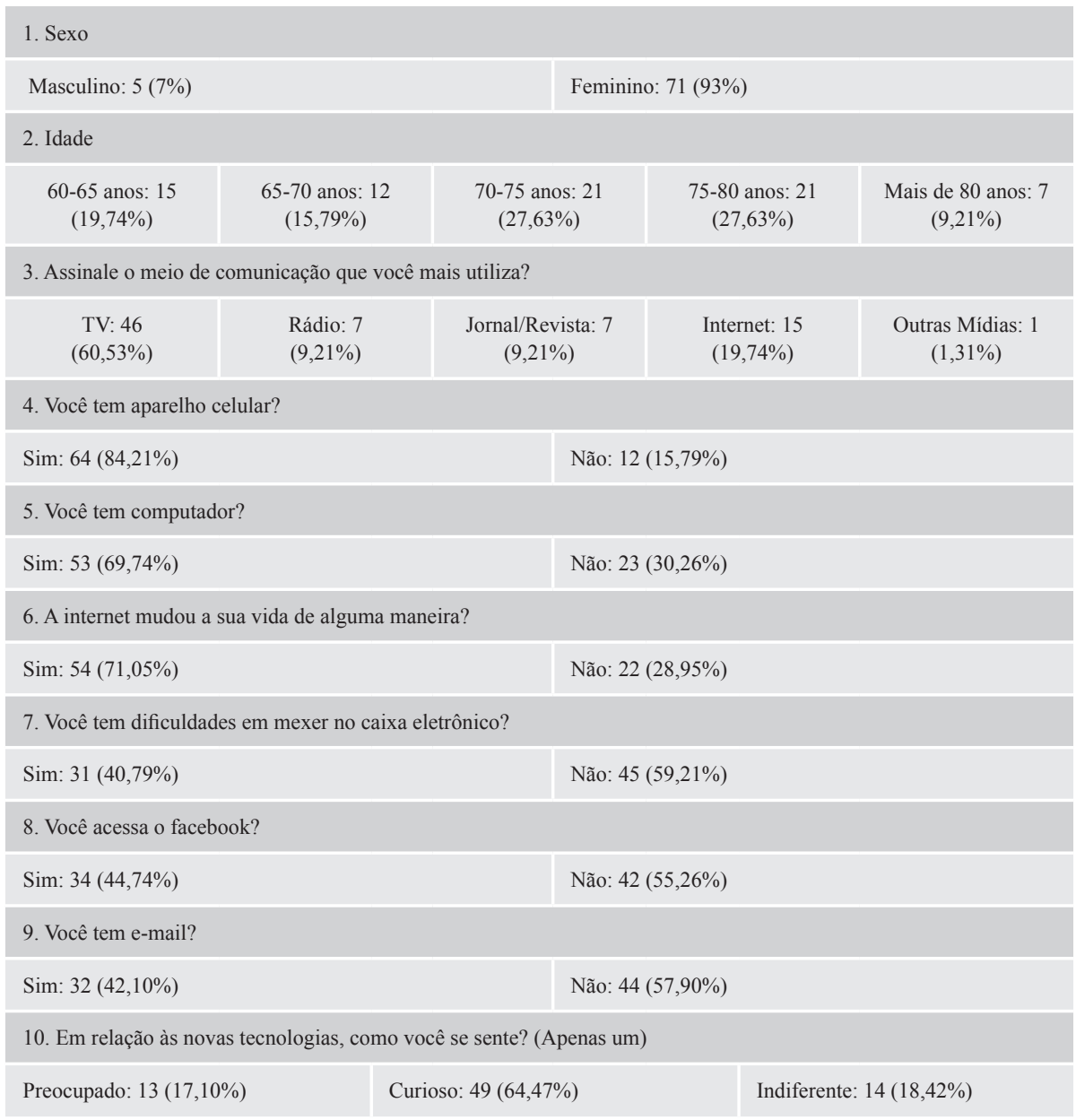

Os números nos revelam alguns dados importantes para caracterizar o grau de apropriação do grupo estudado acerca das tecnologias de comunicação. Se a TV ainda é a mídia mais utilizada por esses idosos, com $60,53 \%$, chama a atenção o fato de a internet conquistar a preferência de $19,74 \%$, superando o rádio, o jornal e outras mídias.
A maioria dos idosos tem computador $(69,74 \%)$ e celular $(84,21 \%)$, no entanto, paradoxalmente, apenas $44,74 \%$ do grupo acessa a rede social facebook e só $42,10 \%$ possuem e-mail.

Os idosos, em sua maior parte $(71,05 \%)$, mostraram que a internet mudou a vida deles de alguma forma. Eles também revelaram que, em relação às novas 
tecnologias, se sentem curiosos $(64,47 \%)$. $\mathrm{Na}$ realidade, como dito anteriormente, a tecnologia vem alterando a dinâmica social dessas pessoas há muito tempo, a tal ponto que $59,21 \%$ dos participantes da oficina afirmaram não ter dificuldades para mexer nos caixas eletrônicos.

Voltando à oficina, depois do preenchimento dos questionários, comentamos acerca da importância das tecnologias de comunicação na vida das pessoas. A turma, então, foi dividida em cinco grupos para participar da dinâmica "Minha primeira vez", em que cada participante descreveu como foi seu primeiro contato com o aparelho celular, o computador, a TV, o cinema e o rádio. Os participantes da oficina discutiram como eles encararam os dispositivos tecnológicos: de forma natural ou com espanto? Os novos aparatos foram vistos como aliados ou inimigos? Depois desse momento de partilha, cada grupo escolheu um representante para apresentar aos demais a síntese da discussão coletiva.

Ao realizar um esforço para recordar como foi seu primeiro contato com o celular, o computador, o rádio, o cinema, a $\mathrm{TV}$, o idoso resgata determinado período histórico, caracterizado por específicas práticas sociais de ser e estar no mundo. Além disso, não há como dissociar essa apropriação midiática da estrutura familiar, da temporalidade social e da competência cultural. A partir desse processo de imbricação, podemos afirmar que a experiência coletiva de sociedade do idoso passa também por sua experiência com as tecnologias de comunicação.

Dessa forma, para entendermos como os meios de comunicação desempenham papel importante no universo do idoso, é fundamental investigar as mediações sociais que o circundam, como a família, a igreja, o bairro, o centro de convivência, enfim, o entorno comunicativo, como nos acentua Jesús Martín-Barbero (2009, p. 261): "Assim, o eixo do debate deve se deslocar dos meios para as mediações, isto é, para as articulações entre práticas de comunicação e movimentos sociais, para as diferentes temporalidades e para a pluralidade de matrizes culturais".

Cada um dos idosos trouxe uma história singular, com seus caminhos percorridos de acordo com sua experiência. Por meio dos relatos, o participante da Uati resgata sua relação com as diferentes tecnologias de comunicação ao longo dos anos. A memória de um sujeito pertencente a determinado núcleo familiar evoca a experiência única ante um evento comunicacional, como, por exemplo, a transmissão de um jogo de Copa do Mundo ou o último capítulo de uma radionovela.

O exercício de recordar envolve o processo de assimilação dos acontecimentos, que exige atribuir sentido aos eventos, registrando situações e personagens que mais interessam. No caso de lembranças oriundas dos meios de comunicação, é interessante observar que as memórias 
não foram centradas apenas no dispositivo tecnológico em si, mas também nos contextos sociais em que ocorriam as apropriações.

Pelos relatos, verificamos também que, muitas vezes, a interpretação do grupo acerca de um acontecimento do passado supera o viés testemunhal do indivíduo, que, mesmo fazendo parte da sua história, privilegia a representação elaborada pelo grupo sobre o fato.

Além da curiosidade, é natural que o surgimento de novas tecnologias possa gerar uma sensação de preocupação ou desconforto, que está associada, muitas vezes, ao receio de ser excluído por não saber utilizar tais dispositivos. Esse temor foi relatado por alguns participantes da oficina, que citaram como exemplo quando a máquina de datilografia foi substituída pelos computadores nos escritórios e o micro-ondas começou a fazer parte dos lares brasileiros.

Outra questão significativa levantada pelos participantes da oficina é a importância de os idosos começarem a lidar com as tecnologias, a fim de se tornarem independentes em suas atividades do cotidiano, garantindo com isso autoconfiança e também melhor qualidade de vida. Alguns deles relataram que utilizar o caixa eletrônico era uma atividade complexa no começo, mas que depois se tornou uma tarefa fácil, que não exige o auxílio de ninguém.

Em relação às mídias digitais, boa parte deles reclamou que as novas gera- ções dedicam muito tempo ao uso desses dispositivos. Alguns afirmaram ter dificuldades em conversar com filhos e netos por causa da atenção voltada quase que exclusivamente ao universo das redes sociais (facebook, whatsapp, twitter, entre outras), que impossiblitam o diálogo face a face entre os familiares.

Observamos ainda que muitos idosos manifestaram um sentimento de saudosismo, que remetia a um tempo em que as pessoas se reuniam para escutar o rádio ou assistir à TV, o que atualmente é raro por conta de nosso cotidiano cada vez mais acelerado e individualista. Fica claro, do ponto de vista dos mais velhos, que quanto maior o desenvolvimento tecnológico, mais as pessoas se distanciam da vida em grupo.

\section{Algumas considerações}

A presença da tecnologia tornou-se imperativa na sociedade desde o começo da humanidade. Inovações, invenções de instrumentos e máquinas sempre acompanharam os seres humanos, desde a era pré-histórica, passando pelas primeiras civilizações, a Idade Média, a modernidade, até chegar aos dias atuais. Assim, desde o princípio, o imaginário, a representação de si, dos outros e do mundo são elaborados a partir de um aparato tecnológico.

Vale ressaltar que a tecnologia em si mesma não tem nenhum problema. A 
questão está no futuro do homem diante do mundo maquínico; está no modo de sermos humanos e de nos relacionarmos. O controle remoto, por exemplo, mudou o hábito de assistir à TV, tornando a troca de canais uma atividade mais cômoda, mas também contribuiu para que nos tornássemos mais sedentários a partir do momento que não precisávamos mais levantar do sofá para executar essa tarefa.

No que se refere aos meios de comunicação, algumas dessas tecnologias surgiram na vida dos idosos de hoje quando eles já eram adultos ou até mesmo velhos, influenciando a relação estabelecida com esses dispositivos. À medida que aumenta a média de idade da população no mundo, a sociedade parece estar ficando cada vez mais midiatizada, o que exige um contínuo processo de aprendizagem desse grupo social.

Acreditamos que os objetivos da oficina de recuperar e fazer o registro de situações relacionadas ao contato com as tecnologias de comunicação foram assimilados pela maioria dos idosos. Por meio do exercício de memória coletiva, o passado foi parcialmente recuperado, provocando uma reflexão nos estudantes da Uati acerca da transformação dos aparatos midiáticos, cada vez mais interativos e presentes na dinâmica social dos núcleos familiares.

Discutir o papel de centralidade que os meios de comunicação assumiram ao longo dos anos na sociedade, desde o rádio até as mídias digitais, nos faz pensar na urgência dos estudos acerca da apropriação social da tecnologia. Novos dispositivos não devem resultar em novos processos de exclusão, principalmente em relação aos mais velhos, que ainda não se adequaram às inovações incorporadas na vida cotidiana.

Recebido em: 3/2/2016

Aprovado em: 18/2/2016

\section{Referências bibliográficas}

BARbOSA, M. C. Comunicação e usos do passado. Logos, Uerj [impresso], n. 22, p. 154162, 2015.

BONDIA, J. L. Notas sobre a experiência e o saber de experiência. Revista Brasileira de Educação [on-line], Rio de Janeiro, n. 19, p. 20-28, 2002.

BOSI, E. Memória e sociedade: lembranças dos velhos. 14. ed. São Paulo: Companhia das Letras, 2007.

CITELli, A.; COSTA, M. C. C. Educomunicação: construindo uma nova área do conhecimento. São Paulo: Paulinas, 2011.

DEBERT, G. G. A reinvenção da velhice: socialização e processos de reprivatização do envelhecimento. São Paulo: Edusp, 2004.

HALBWACHS, M. A memória coletiva. São Paulo: Centauro, 2006.

HJARVARD, S. Midiatização: teorizando a mídia como agente de mudança social e cul- 
tural. Matrizes, São Paulo, v. 5, n. 2, p. 53-91, jan./jun. 2012.

INSTITUTO BRASILEIRO DE GEOGRAFIA E ESTATÍSTICA(IBGE). Censo demográfico, 2010.

LE GOFF, J. História e memória. 5. ed. Campinas: Ed. da Unicamp, 2003.

MARTÍN-BARBERO, J. Dos meios às mediações: comunicação, cultura e hegemonia. 6. ed. Rio de Janeiro: Ed. da UFRJ, 2009.
MORAGAS. R. M. Gerontologia social: envelhecimento e qualidade de vida. 3. ed. São Paulo: Paulinas, 2010.

NOVAES, M. H. Artimanhas e segredos da memória. In: NEGREIROS, T. C. G. M. (Org.). A nova velhice: uma visão multidisciplinar. 2. ed. Rio de Janeiro: Revinter, 2007.

SILVA, M. L. O. et al. Por uma universidade aberta à participação do idoso. Serviço Social \& Saúde, Campinas, v. 14, n. 1 (19), p. 27-38, jan./jun. 2015. 